\title{
Synthetic study of ravidomycin, a hybrid natural product $^{*}$
}

\author{
Keisuke Suzuki \\ Department of Chemistry, Tokyo Institute of Technology, and CREST, JST, 2-12-1, \\ O-okayama, Meguro-ku, Tokyo 152-8551, Japan
}

\begin{abstract}
Strategies and tactics associated with the total synthesis of hybrid natural products are discussed. The target is ravidomycin (2), one of the gilvocarcin-class antitumor antibiotics with an aryl $C$-glycoside structure. The first total synthesis of $\mathbf{2}$, which was achieved along similar lines of that of gilvocarcin V (1), served for the determination of the relative as well as the absolute stereochemistry of $\mathbf{2}$. Also revealed was a limitation of the synthetic scheme so long as the amino sugar congener was concerned. A preliminary result is discussed on the $[2+2+2]$ approach that relies on the ready availability of various benzocyclobutene derivatives via regioselective $[2+2]$ cycloaddition of $\alpha$-alkoxybenzynes and ketene silyl acetals.
\end{abstract}

\section{INTRODUCTION}

Gilvocarcin V (1) and ravidomycin (2) represent a class of aryl $C$-glycoside antitumor antibiotics, sharing a benzonaphthopyranone tetracycle and differing in the sugar at the $\mathrm{C}(4)$ position (i. e., a fucose for $\mathbf{1}$, while an amino sugar for $\mathbf{2}$, Fig. 1). In our continuing synthetic study on this class of natural products [1], our current attention is focused on the amino sugar congener $\mathbf{2}$. The presence of an amino function reinforces the biological activity of the molecule, but at the same time makes the synthesis far more challenging. Additionally, we hoped that the synthesis would contribute to the solution of stereochemical issues associated with 2, (1) the absolute stereochemistry was unassigned, and (2) the original relative stereochemical assignment had been questioned.

Described herein is our synthetic studies directed toward the total synthesis of $\mathbf{2}$.

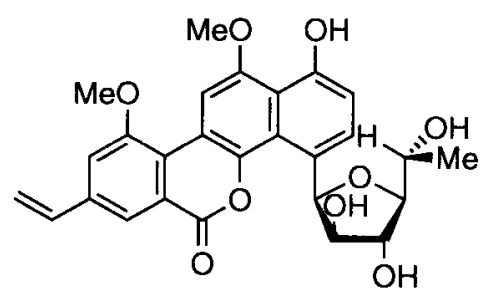

1<smiles></smiles>

2

Fig 1

\footnotetext{
*Lecture presented at the $13^{\text {th }}$ International Conference on Organic Synthesis (ICOS-13), Warsaw, Poland, 1-5 July 2000. Other presentations are published in this issue, pp. 1577-1797.
} 


\section{OUTLINE OF TOTAL SYNTHESIS OF THE GILVOCARCINS}

Before discussing the synthesis of $\mathbf{2}$, it might be appropriate to outline our synthesis of ent-gilvocarcin $\mathrm{M}$ (3) that is the $\mathrm{C}(8)$-methyl congener of $\mathbf{1}$ (Scheme 1). The first step is the $C$-glycosylation of the iodinated resorcinol derivative $\mathbf{5}$ with the fucose acetate $\mathbf{4}$ in the presence of the Hf-based promoter. An essential feature is the regioselectivity of the aryl $C$-glycoside bond formation that occurs at the ortho position to the phenol. After conversion of the phenol $\mathbf{6}$ to the corresponding triflate, the resulting iodo triflate served for effectively generating a benzyne species by treatment with BuLi at $-78^{\circ} \mathrm{C}$. The benzyne, thus generated, undergoes a cycloaddition to 2-methoxyfuran in regioselective manner to give the cycloadduct 7 . Acylation of the naphthalenetriol 7 by an iodobenzoic acid followed Pd-catalyzed cyclization set up the tetracyclic structure of $\mathbf{3}$ [1].

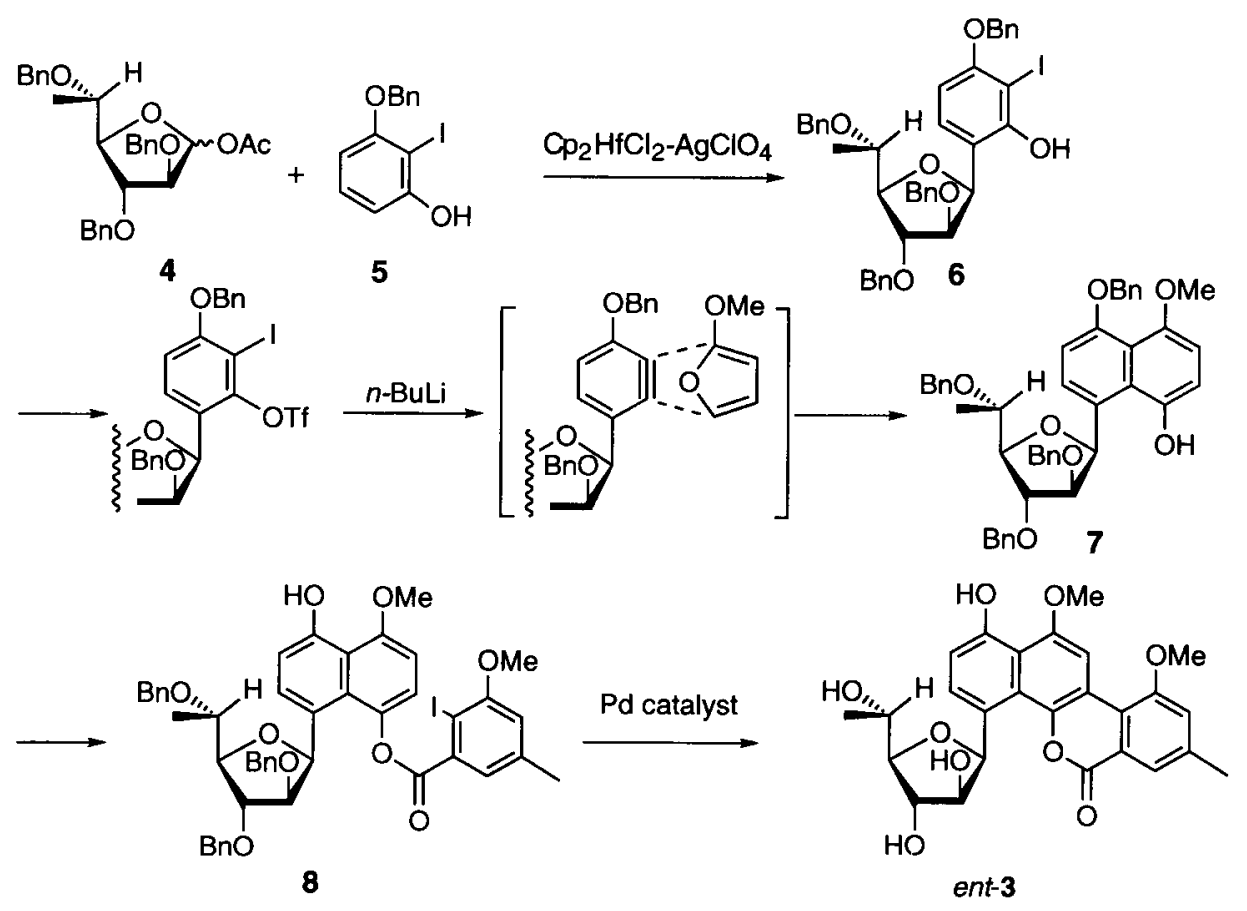

Scheme 1

\section{FIRST TOTAL SYNTHESIS OF RAVIDOMYCIN}

Scheme 2 shows the retrosynthetic analysis of 2 along the similar lines as above. The primary issue was the presence of the dimethylamino function, which seemed incompatible with the benzyne chemistry. Thus, we chose to introduce the amino function at a later stage of the synthetic scheme with an inversion of configuration, and the aryl $C$-glycoside $\mathbf{1 0}$ was set as the early synthetic intermediate.

The problem at this stage of $\mathbf{1 0}$ was the stereochemical control. If the general stereochemical behavior of aryl $C$-glycosides [2] were taken into consideration, there was no obvious preference of the anomers of this intermediate 10. However, we previously reported that the use of a bulky silyl group for the protection of such aryl $C$-glycosides could bring about an impressive change in the stereochemical trend [3], and this trick was used for the stereocontrol in this particular instance.

Starting from readily available D-glucurono- $\delta$-lactone, several steps of conversion gave the glycosyl donor $\mathbf{1 1}$ armed with a $t$-butyldiphenylsilyl group and installed as a stereocontrolling factor. Indeed, the $C$-glycoside formation of $\mathbf{1 1}$ went nicely to give $\mathbf{1 2}$ as a sole product (Scheme 3). 


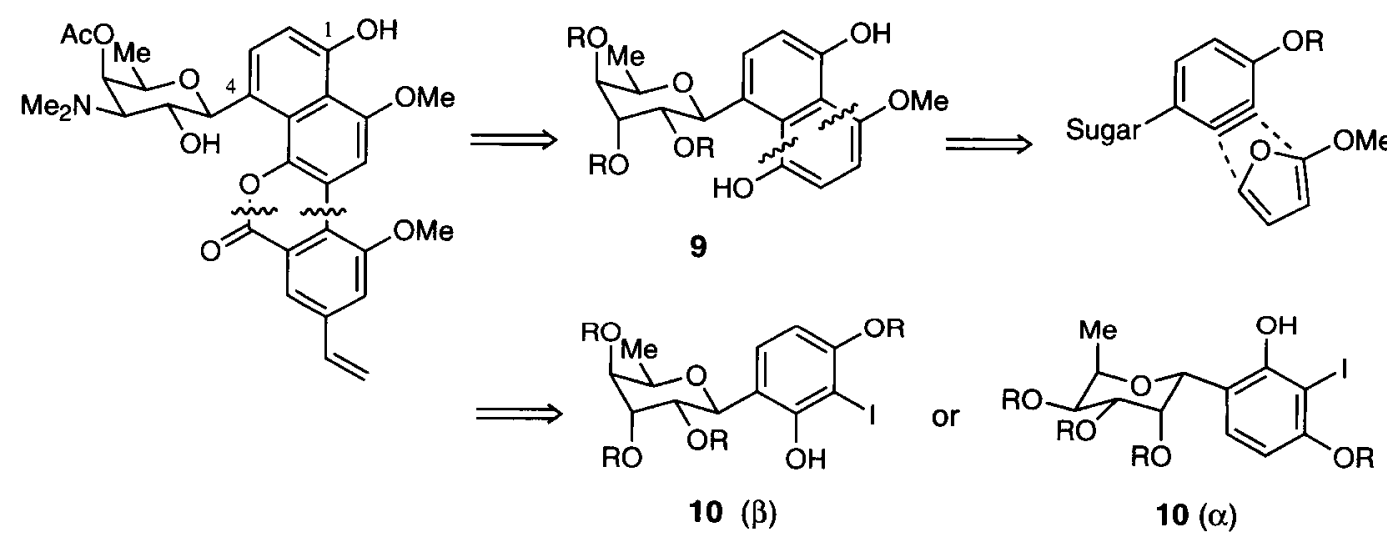

Scheme 2

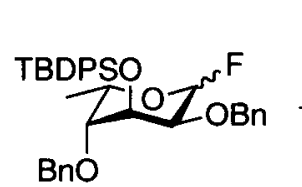

11<smiles>Oc1cccc(Br)c1I</smiles>

5<smiles>COCCc1cc(OC)c(C(=O)Oc2ccc(OCc3ccccc3)c3c(OCc4ccccc4)ccc(OC)c23)c(OC)c1</smiles>

14<smiles>COCCc1cc(OC)c2c(c1)c(=O)oc1c(OCC(C)C(C)COC)ccc(OC)c12</smiles>

15

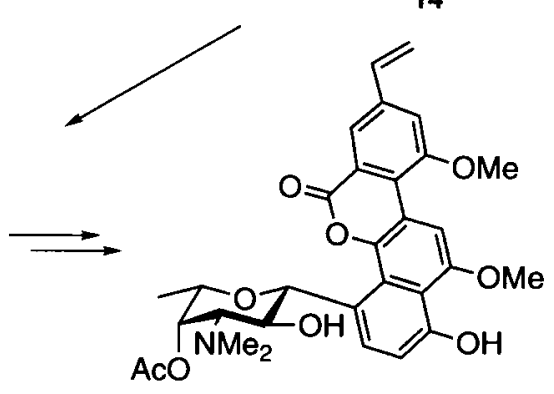

ent-2

Scheme 3

Subsequent conversion including a benzyne-furan cycloaddition [4], introduction of the amino group and cyclization allowed the first total synthesis of ravidomycin. The final product was fully consistent with the natural product, except for the sign of $[\alpha]_{D}$ value. Thus, the synthesis established the stereochemistry of $\mathbf{2}$ in terms of the relative sense (the C5 stereochemistry was originally misassigned) and the absolute sense (the synthetic material was the enantiomeric to the natural product [5]). 


\section{[2+2+2] APPROACH TO RAVIDOMYCIN}

A lesson from the above synthesis was that the mere presence of an amino group makes the synthesis much longer ( 6 steps for $\mathbf{1}$ with a neutral sugar, 18 steps for $\mathbf{2}$ with a $\mathrm{Me}_{2} \mathrm{~N}$-function). Hoping to develop a straightforward route to 2 , we became interested in a [2+2+2] approach (Scheme 4).<smiles>C=Cc1cc(OC)c2c(c1)c(=O)oc1c(OC)c(O)cc(O)c12</smiles><smiles>C=Cc1cc(OC)c(C(=O)O)c(C(=O)O)c1</smiles>

\section{Scheme 4}

The first step is the [2+2] cycloaddition of an $\alpha$-alkoxybenzyne to an olefin. Ketene silyl acetal worked nicely as an olefinic component in this cycloaddition, with the rigorous regioselectivity in a way that the silyl acetal moiety comes near to the alkoxy group of the benzyne (Scheme 5) [6]. The regioselectivity persisted for a variety of ketene silyl acetals, thereby making accessible various benzocyclobutenes of synthetic versatility. We are currently working in this direction.

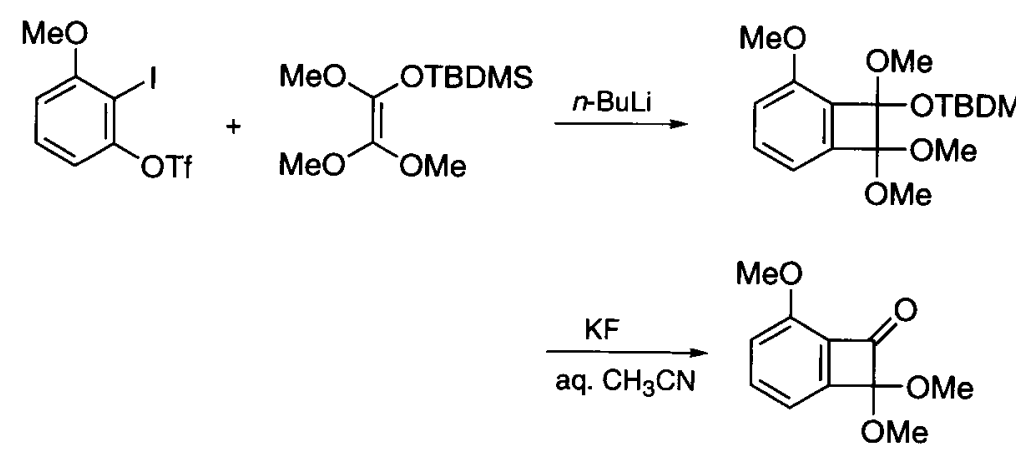

Scheme 5

\section{ACKNOWLEDGMENT}

I express my gratitude to my coworkers whose names appear in references.

\section{REFERENCES}

1. T. Matsumoto, T. Hosoya, K. Suzuki. J. Am. Chem. Soc. 114, 3568-3570 (1992); T. Hosoya, E. Takashiro, T. Matsumoto, K. Suzuki. Ibid. 116, 1004-1015 (1994).

2. K. Suzuki. Pure Appl. Chem. 66, 2175-2178 (1994).

3. T. Hosoya, Y. Ohashi, T. Matsumoto, K. Suzuki. Tetrahedron Lett. 37, 637-640 (1996).

4. T. Matsumoto, T. Hosoya, M. Katsuki, K. Suzuki. Tetrahedron Lett. 32, 6735-6736 (1991).

5. S. Futagami, Y. Ohashi, K. Imura, T. Hosoya, K. Ohmori, T. Matsumoto, K. Suzuki. Tetrahedron Lett. 41, 1063-1067 (2000).

6. T. Hosoya, T. Hasegawa, Y. Kuriyama, T. Matsumoto, K. Suzuki. Synlett. 177-179 (1995);

T. Hosoya, T. Hasegawa, Y. Kuriyama, K. Suzuki. Tetrahedron Lett. 36, 3377-3380 (1995);

T. Hosoya, T. Hamura, Y. Kuriyama, M. Miyamoto, T. Matsumoto, K. Suzuki. Synlett. 520-522 (2000). 